\title{
Near optimal processing of information during concept identification
}

\author{
M. J. KLINGSPORN, C. R. PETERS, M. P. ENNS AND RALPH ILES
}

WICHITA STATE UNIVERSITY

Subjects were taught a code in order to alleviate storage load during a concept identification problem. While using this code Ss performed about as expected from an information processing point of view but still showed some toss of information. Knowledgeable $S$ s performed better than more naive ones

Hovland \& Weiss (1953) and Cahill \& Hovland (1960) present evidence that memory limitations are critical to "good" concept identification (CI) performance. It could be argued that if memory load were reduced, the $S$ could assimilate all information presented him and solve the concept in the minimal number of trials, as Hovland and Weiss' Ss did in the case of all positive instances. The simple Type I (Shepard, Hovland, \& Jenkins, 1961) CI task with four binary valued dimenslons was selected as being of sufficient complexity to be nontrivial but of sufficient simplicity to minimize memory load. Furthermore, a code was employed to minimize storage load (possibly at the expense of inferential processes) as woll as a systematic technique of ordering the stimulus patterns in a sequence that removed all redundancy (see Table 1) in the present experiment. This sequence is similar to Levine's (1966) " internally orthogonal sets" except it is expanded and rotatable so that any sequence of length 3 would allow a "perfect information retainer and analyzer" (Levine, 1966) to infer the correct concept.

\section{Materiais}

Part of one of the two lists of stimulus materials is shown in Table 1 (left column) along with its coded values on the four dimensions (right column). Two such lists of 16 items each were used. It should be noted that, beginning with the second item, if it and the next two items were positive $(t,+,+)$ the concept was "formal." Similarly the outcomes $(+,+,-)$ and $(t,-,+)$ would occur if the concepts were "male" and "old," respectively. Each of the eight possible outcomes represent a distinct concept, and the entire list was such that this correspondence obtained for any sequential triplet, including the last, first, and second (i.e., the list could be rotated).

The meaning of the first two coded values listed is clear. The third refers to whether or not the relation between the speaker and referent is horizontal (have same family status) or vertical. The last value refers to language style, whether the stimulus is a formal or colloquial expression.

\section{Procedure and Predictions}

Subjects of differing degrees of sophistication were desired. Twelve Ss were used. Four were the authors, four were graduate students, and four were undergraduates. The Ss were tested individually. Before being tested, each $S$ was drilled until he could readily identify the complement of each stimulus as well as the four coded values represented by each stimulus (20-30 $\mathrm{min}$ of rehearsal). Following this practice, each $S$ was given one practice problem followed by 40 test problems. The correct concept was randomized across problems except that each value occurred as the concept five times for each $S$. As soon as the $S$ responded to the hypothetical question "Is the value present?" he was given informative feedback and the stimulus was removed from his view. Immediately the second stimulus was presented to S.

Subjects were informed that errors need not be made following the third trial of any problem, that their responses would pace the experiment, and that correct responses were more important than speed.

If Ss processed all information made available to them, errors would occur independently with $p=0.5$ on each of the first three trials and never thereafter. This assumption allows predictions of the summary statistic $L$, the trial number of the last error before solution of any problem. It was thought that sophisticated Ss would be more inclined to function as optimal information processors than naive Ss. Results and Discussion

The main result is the generally good fit between values predicted by an information processing model and those obtained. Figure 1 gives the predicted L distribution and the obtained distributions for each of the three groups. In spite of the generally good fit, it is evident that Ss in general suffer some failures and do not process all of the information made avallable to them.

Comparisons were made between groups regardTable 1.

Partial List of Stimulus Materials Showing Order and Coded Values

Stimulus

Coded Values
Dad

Husband

Son

Mother

Missy
Old, Male, Vertical, Colloquial

Old, Male, Horizontal, Formal

Young, Male, Vertical, Formal

Old, Femole, Vertical, Formal

Young, Female, Vertical, Colloquial 


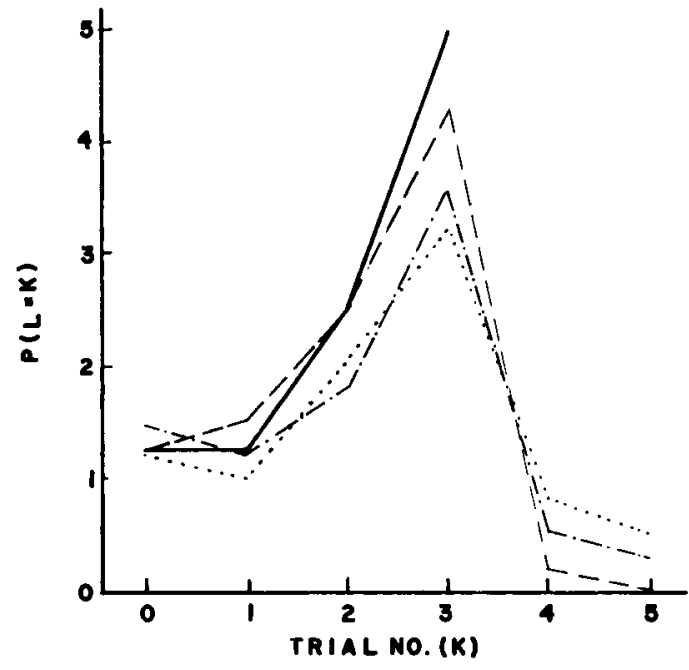

Fig. 1. Distribution of trial number of last error. Heavy solid line indicates predicted values. Groups indicated as follows: dashed line authors; dotted line - undergraduates; combination - graduates. $L=0$ indicates the problem was solved without errors.

ing the number of problems in which the final error occurred following the third trial. While the graduate students performed a bit better than the undergraduates, this difference was not significant $\left(X^{2}=1.8\right.$, $\mathrm{df}=1, \mathrm{p}>.10)$. The authors, however, did perform significantly better than the combined student groups $\left(x^{2}=26.3\right.$, $\left.d f=1, p<.001\right)$, demonstrating the relevance of sophistication to the successful adoption of an information processing strategy. This group difference must be qualified in that three of the graduate students and two of the undergraduates performed about as well as the authors.

While the design of the study was such that Ss could accumulate all the requisite information by storing each stimulus along with its category (exemplar or nonexemplar) for each of the first three trials and then infer the solution, it became apparent from the S's pacing of the trials as well as from postexperimental discussion that some Ss decoded in process, eliminating half of the dimensions after each informative feedback. Insofar as Ss behaved in this manner, the code was of no benefit (perhaps a handicap) and they could best be described by Levine's (1966) information processing theory. To show that such decoding and eliminating of dimensions after each trial was not a necessary behavioral strategy, a subsequent study was performed on two of the more successful graduate students, the senior author, and one new S. In this second study, 40 problems were given as follows: For 20 problems, the information regarding the respective categorizations of the three stimuli were given prior to the sequential presentation of the three stimulus patterns, presented rapidly (about $1 \mathrm{sec}$ each), whereupon $\mathrm{S}$ was allowed as much time as required to report the concept. On the other 20 problems all the categorical information was given following the presentation of the third stimulus pattern.

Since the errors across these 40 problems for each $S$ were comparable to the failures found in the original CI study, one must conclude that decoding in process was not a necessary strategy. Furthermore, this consistency in failing to process all the needed information under conditions of different memory loads suggests that storage per se is not the critical factor but rather some interaction between the storage and the decoding of the information.

\section{References}

CAHILl, H. E., \& HOVLAND, C. I. The role of memory in the acquisition of concepts. J. exp. Psychol., 1960, 59, 137-144.

HOVLAND, C. I., \& WEISS, W. Transmission of information concerning concepts through positive and negative instances. J. exp. Psychoh, $1953,45,165-182$.

LEVINE, M. Hypothesis behavior by humans during discrimination learning. J. exp. Psychol., 1966, .71, 331-338.

SHEPARD, R. N., HOVLAND, C. I., \& JENKINS, H. N. Learning and memorizations of classifications. Psychol Monogr., 1961, 75, No. 13 (Whole No. 517). 